\title{
STUDENTS' GEOMETRIC THINKING WITH CUBE REPRESENTATIONS: ASSESSMENT FRAMEWORK AND EMPIRICAL EVIDENCE
}

\author{
Taro Fujita ${ }^{1}$, Yutaka Kondo ${ }^{2}$, Hiroyuki Kumakura ${ }^{3} \&$ Susumu Kunimune $^{3}$ \\ ${ }^{1}$ University of Exeter, UK; ${ }^{2}$ Nara University of Education, Japan; ${ }^{3}$ Shizuoka \\ University, Japan
}

The order of authors is strictly alphabetical. All authors contributed equally to this manuscript.

While representations of $3 D$ shapes are used in the teaching of geometry in lower secondary school, it is known that such representations can provide difficulties for students. In order to assess students' thinking about 3D shapes, we constructed an assessment framework based on existing research studies and data from G7-9 students (aged 12-15). We then applied our framework to assess students' geometric thinking in lessons. We report two cases of qualitative findings from a classroom experiment in which Grade 7 students (aged 12-13) tackled a problem in $3 D$ geometry that was, for them, quite challenging. We found that students who failed to answer given problems did not mentally manipulate representations effectively, while others could mentally manipulate representations and reason about them in order to reach correct solutions. We conclude with the proposition that this finding shows the framework can be used by teachers in instruction to assess their students' $3 D$ geometric thinking.

Keywords: Geometrical thinking, 3D geometry, Geometrical manipulations, Geometrical representations, Geometrical reasoning, Assessment framework

\section{Introduction}

The episode shown in Figure 1 was observed in one of the authors' geometry classes for trainee teachers in primary schools.

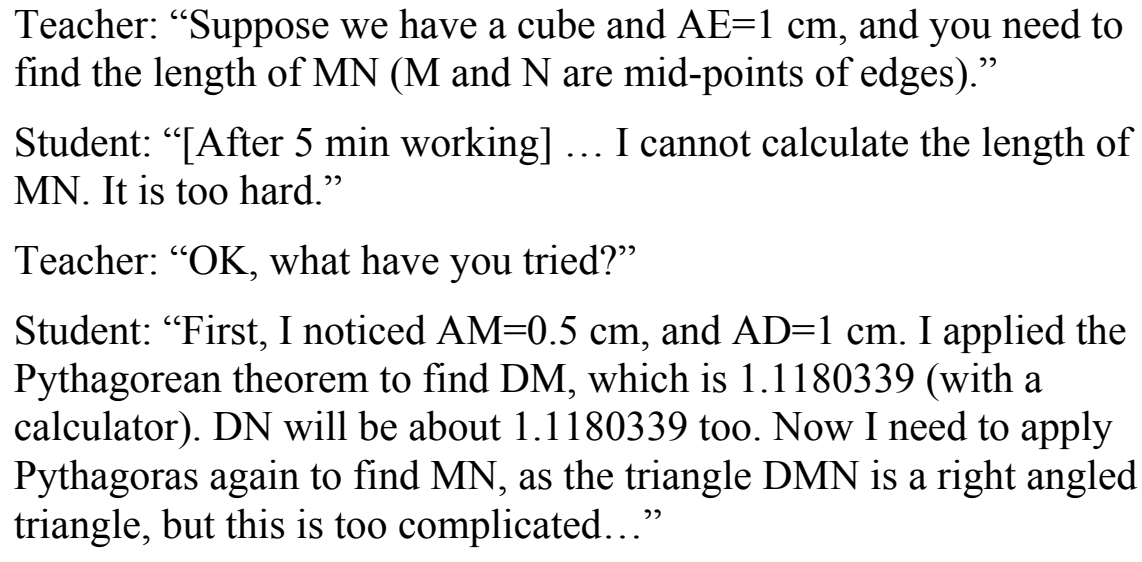

Figure 1: Student's thinking with 3D representation

The student quoted in the episode, and many others in the class, did not recognise that $\mathrm{MN}$ is the same as $\mathrm{AC}$ and therefore the length of $\mathrm{MN}$ is $\sqrt{2} \mathrm{~cm}$. Instead, they saw 
triangle DMN as a right-angled triangle, and tried to use the Pythagorean Theorem to calculate the length MN.

Küchemann and Hoyles (2006) suggest that to solve geometrical tasks with reasoning it is important to consider how to support students "to balance their need to be rigorous with the use of spatial intuition" (p. 604). As this episode illustrates, students can have difficulties in interpreting 3D representations, and, as such, more attention needs to be paid to how students reason about 3D shapes when they are undertaking problems in mathematics as well as other subjects (such as design and technology). It is especially important to focus on $2 \mathrm{D}$ representations of $3 \mathrm{D}$ shapes as these can be the main mediational means (for example, on the classroom board or in textbooks or other teaching materials).

The teaching of geometry provides both a fundamental means of developing learners' spatial visualisation skills and a vehicle for developing their capacity with deductive reasoning and proving (Battista, 2007; Royal Society, 2001). Also, most school curricula aim to develop learners' understanding of 3D figures. As such, seeking ways to develop and assess learners' spatial thinking in 3D geometry is an important research area with one long-standing topic being how learners' reasoning is influenced by the ways in which geometric objects are represented (see Godfrey, 1910; Ben-Chaim, et al, 1989; Hershkowitz, 1990; Mesquita, 1998). While the term 'representation' can refer to internal (mental) and to external (concrete) representations, in this paper our focus is on how students reason and make use of 3D shape properties through external representations such as the various representations of a cube in Figure 2. Our particular case of interest is when the geometric object being represented is three-dimensional while the medium of representation is two-dimensional (as is necessarily the case in this article), and our target educational stage is from upper primary to lower secondary, when students start learning more geometry more formally with various forms of mathematical reasoning and manipulations of shapes.

In order to scrutinise students' thinking with representations of 3D shapes, our aim is to deepen understanding of how students use representations in order to deduce information and solve geometric problems with cubes. We chose a cube to exemplify students' thinking because a) it is one of the familiar 3D shapes for many students, b) it can be a source of problem solving in geometry and c) even when problem solving with cubes students demonstrate a greater variety of forms of thinking and strategies than we expect. We address the following two research questions (RQ):

- RQ1: What assessment framework can be constructed to assess students' geometric thinking when they are solving $3 \mathrm{D}$ geometry problems with $2 \mathrm{D}$ representations?

- RQ2: How can we apply this framework to assess various forms of students' geometrical thinking in geometry lessons? 
Sections 2-5 address research question 1 . We take as our starting point a brief exploration of the different types of representations students may encounter and their different forms of thinking with them. In reviewing existing studies we examine two themes, 'nature of 3D representations' and 'manipulation of 3D representations', in order to develop a detailed assessment framework of students' thinking with 3D shapes in relation to their interpretation of diagrammatic information (Bishop, 1983). We propose our assessment framework is a new way to better capture students' thinking when they solve 3D geometry problems with $2 \mathrm{D}$ representations. To construct our framework, we take a bottom-up approach in that it is derived primarily from data from a set of assessment questions answered by 1025 students in Grade 7-9. In section 6-7 we apply our framework to classroom episodes taken from four lessons from a teaching experiment with Grade 7 students (addressing research question 2). In considering how our framework could be useful to assess various forms of students' geometrical thinking in geometry lessons, and in applying these findings, we discuss how we can characterise students' thinking, and what actions our insights might lead us to take in terms of how we might advance students' thinking with 3D shapes - a form of mathematical thinking that is known to be challenging for many students (e.g. Ben-Chaim, et al, 1989; Widder and Gorsky, 2013).

\section{3D geometrical thinking - Existing knowledge and gaps}

\subsection{Geometrical thinking with representations of 3D shapes}

Beginning with the theme of the nature of $3 \mathrm{D}$ representations, one phenomenon related to learners' understanding of geometric representations is the well-established 'prototype effect' by which a certain representation is judged more representative than another (Hershkowitz, 1990, p. 82; Fujita, 2012). Due to this 'effect', learners are much better at recognising isosceles triangles that are 'standing on their base' than ones that are presented in a different orientation. A variety of methods are available for representing $3 \mathrm{D}$ geometric objects such as a cube on a two-dimensional medium such as paper or the classroom board. Perhaps the most classical representation of a cube in two dimensions is the oblique parallel perspective, in which parallels sides are drawn as parallels edges and one face of the cube is drawn as a square. Figure 2 shows two orthogonal projections ( $a$ and $b$ ) and an example of an oblique parallel projection (c).

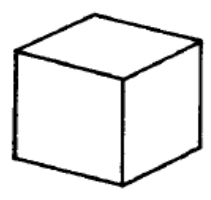

(a)

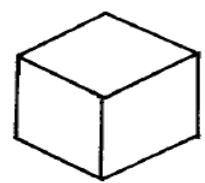

(b)

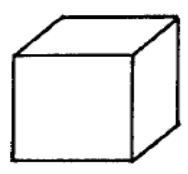

(c)

Figure 2: orthogonal and oblique parallel projections of the cube 
Another convention is the use of dotted lines to show the 'hidden' edges of the cube (as in Figure 1).

Existing research evidence indicates that representations of $3 \mathrm{D}$ shapes can have various impacts on learners' reasoning processes. Parzysz (1988; 1991), for example, reported that not only do learners prefer the parallel perspective (as compared to projective representations) but, in particular, learners prefer the oblique parallel perspective in which the cube is drawn with one face as a square. An important issue that this oblique parallel perspective representation raises for research in geometry education is the way in which learners' reasoning might be influenced by the manner in which representations are presented (such as in Figure 1) given the difficulties pupils have with 3D representations even when 3D dynamic geometry software is available (Mithalal, 2009).

Fischbein (1987, p. 41) argued that a "productive reasoning process" aims at solving a "genuine problem". He suggested that in productive reasoning "images and concepts interact intimately" (Fischbein, 1993, p. 144). By this we surmise that Fischbein is referring to the notion of 'figural concept' as capturing the combined role of the figural and the conceptual in geometry. As Mesquita (1998) explains, an external representation of a geometrical problem does not, by itself, enable someone to solve a geometric problem, but it may contribute to the problem-solver's definition of the structure of the problem. One way this happens, according to Mesquita, is when the representation gives support to geometrical intuition, which in some situations can be very powerful by helping individuals "to apprehend relationships among geometrical objects" (p. 184). Yet, Mesquita goes on to show, external representations can lead to some ambiguities with the result that particular geometrical relationships might appear as 'evident' to students in a way that can prevent geometrical reasoning from developing. What Mesquita calls the double status of a geometrical representation is that it can represent "either an abstract geometrical object, or a particular concretization" (p. 186). It is this double status that impacts student reasoning.

For the theme of the manipulation of 3D representations, the evidence above suggests that, for a particular geometry problem that makes use of a particular representation, students may or may not invoke theorems or properties that their teacher might expect them to use to form, and then prove, a conjecture. This is because the representations may - or may not - appear to the students as 'typical'. In cases like these, as Mesquita (1998) suggested, an external representation may become an 'obstacle' to student understanding.

\subsection{Existing research on interpreting 3D shape representations}

Researchers have proposed a variety of ways to categorise capacities for 3D geometric thinking. For example, van Nes and van Eerde (2010, p. 146-7) argue that 'spatial 
sense' has three components: 'spatial visualization' (the capacity to picture mentally the movements of 2D and 3D objects), 'spatial orientation' (the capacity to change the frame of reference with respect to the environment), and 'shape' (the capacity to manipulate mentally spatial forms from a fixed perspective). Spatial capacities proposed by Pittalis and Christou (2010) are similar to van Nes and van Eerde, but they also identified five additional capacities that they argue are more specific to 3D geometrical thinking: 'to manipulate different representational modes of 3D objects'; 'to recognise and construct nets'; 'to structure 3D arrays of cubes'; 'to recognise 3D shapes' properties and compare 3D shapes'; and 'to calculate the volume and the area of solids' (ibid pp. 193-4). Their study found that 3D geometrical thinking can be described by four types of reasoning: reasoning related to the representations of 3D objects; spatial structuring; conceptualisation of mathematical properties; and measurement.

In terms of interpreting 3D shape representations, Pittalis and Christou (2013) studied learners constructing 2D representations of 3D shapes (such as nets) and interpreting structural elements or properties of 3D shapes (such as enumerating the vertices/faces/edges of 3D shapes or recognising parallel/perpendicular faces/edges). They found that when interpreting representations of 3D figures, learners utilise two capabilities: 'recognising the properties of 3D shapes and comparing 3D objects' and 'manipulating different representational models of 3D objects'.

\subsection{The need to further analyse $3 \mathrm{D}$ geometrical thinking}

Existing research provides a way forward for analyzing 3D geometric thinking. However, it has not fully captured aspects of students' thinking process when they face a challenging problem together with being given a $3 \mathrm{D}$ representation (such as Figure 1) that requires capability to reason beyond recognising properties such as parallel/perpendicular faces/edges. We can illustrate the issue by considering the geometric problem set out in Figure 3.

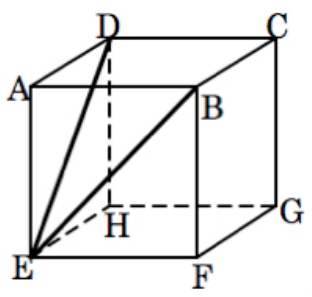

What is the size of the angle BED?

How did you determine the angle measure?

Figure 3: angle in a cube problem (survey problem version)

The existing literature reviewed above suggests that when working with problems with given 3D shape representations, two capacities are particularly important for working with their construction of internal representations and use of them in their problem solving: the capability to manipulate the representation and the ability to reason with the properties of shapes. By 'manipulating representations' we mean the 
capacity mentally to add lines, edges, faces, etc., and change orientations from, for example, orthogonal to oblique parallel projections, to imagine a net of given representations, and so on. This might be observed when learners actually interact with the given external representations, e.g. using a pen to draw lines on the given representations. To solve the problem in Figure 3, one approach is to draw the line $\mathrm{DB}$, deduce that triangle $\mathrm{BDE}$ is an equilateral triangle, and then conclude that angle $\mathrm{BED}$ is 60 degrees. Here, drawing a line DB can be seen as a productive manipulation to the figure that allows the student to reason about angle BED using the newly formed triangle BED. In this paper, we take 3D geometric thinking as mental processes which involve both manipulations and reasoning about $3 \mathrm{D}$ geometric figures and their properties.

With these two capacities in mind, and using data from part of our larger-scale study of the geometrical thinking of 570 students from Grades 7-9 in Japan (Kumakura, et al, 2000; Jones, et al. 2012), we undertook an initial analysis of responses to the question shown in Figure 3. We found that students' incorrect responses were the result either of faulty reasoning with 3D shapes' properties or faulty manipulations of shapes, or both. Not all manipulations and interpretations of the given representations were useful, and this echoes what existing studies suggest; that is, "visualizations are more beneficial if they also support human reasoning" (Huang, 2009, p. 150). Overall we found similar behaviours to the types identified by Pittalis and Christou (2013). As such, we could classify students' answers into the following five categories:

(A1) no answer (15.4\%).

(A2) incorrect answer led by 2-dimensional or intuitive global judgment; answers such as $30^{\circ}$ with no reason stated $(20.0 \%)$;

(A3) incorrect answer led by intuitive knowledge and visual information; answers such as half of $\angle \mathrm{DEB}=90 / 2=45^{\circ}(41.8 \%)$;

(B) incorrect answer with some manipulations of a cube but influenced by visual information; answers such as drawing a net, and then $45^{\circ}+45^{\circ}=90^{\circ}(10.7 \%)$;

(C) incorrect answer by using sections of cube but influenced by intuitive knowledge and visual information; answers such as in triangle $\mathrm{BDE}, \angle \mathrm{B}=\angle \mathrm{D}=45^{\circ}$, therefore $\angle$ $\mathrm{DEB}=90^{\circ}(5.1 \%)$;

(D) correct answer with valid reasoning; answers such as in triangle BDE, $\mathrm{DE}=\mathrm{EB}=\mathrm{BD}$ and therefore $\angle \mathrm{BED}=60^{\circ}(7.0 \%) \cdot$

Our analysis indicates that it is difficult for many students in G7-9 to reason correctly with a given representation. This finding warrants further investigation - in particular we need to construct a comprehensive assessment framework when students undertake problem solving with 3D shapes, at the educational stage when students are in G7-9 in lower secondary schools. In the next section, we describe our methods for constructing such an assessment framework. 


\section{Methods}

\subsection{Context}

This study of 3D geometric thinking is situated within a larger study that demonstrates how geometry teaching plays a role in developing students' ideas about geometrical figures in Japan in Grades 8 and 9 in geometrical proof and proving, as illustrated by the curriculum used in primary and lower secondary schools in Japan (emphasis added, as explained below):

- In primary school (Grades 1-6), basic properties of plane and solid figures are studied informally, mainly in relation to everyday life objects. Students also start developing their drawing skills to represent $3 D$ shapes on a $2 D$ plane;

- In Grade 7, students (aged 12-13) study geometrical constructions, symmetry, and selected properties of solid figures (names of $3 D$ shapes, nets, sections of cube, surface areas and volume) informally, but logically, to establish the basis of the learning of proof (note that the measure of the angle between two lines in $3 D$ space is not formally considered);

- In Grade 8, students (aged 13-14) are introduced to formal proof through studying properties of angles, lines, congruent triangles, and parallelograms, during which they learn the structure of proofs, how to construct proofs, and how to explore and prove properties of triangles and quadrilaterals including inclusion relationships between these;

- In Grade 9, students (aged 14-15) study similar figures and properties of circles, drawing on their consolidated capacity to use proof in geometry and Pythagorean Theorem with both 2D and $3 D$ shapes.

As evident in this progression, while primary students make some informal study of 3D shapes (shown in italics above), students in Japanese lower secondary school have relatively limited opportunities to study and explore 3D geometry. As a consequence, secondary school students tend to have difficulties when they are faced with 3D geometry problems (for instance, when, in Grade 9, they are finding the lengths of a diagonal of a cube by utilising the Pythagorean Theorem).

\subsection{Assessment questions}

In order to study students' 3D geometrical thinking, we devised a set of problem solving questions. Given the advice of Widder and Gorsky $(2013$, p. 97) to include items that probe "understanding based on given verbal information and logical analytical thinking" (what they call a-type items) and items that probe "understanding based on visualization" (that is, the mental manipulation of a given geometric configuration; what they call b-type items), we designed our assessment to include both types of understanding, i.e. the questions required both logical analytical thinking 
and mental manipulations. For example, in order to solve Q1, students must first visualise angle $\mathrm{ABC}$ and then activate their knowledge of properties of cubes. For Q2-(2) students undertake a simple manipulation, e.g. mentally seeing $\mathrm{CD}$ as a diagonal of the face, and then reason $\mathrm{CD}$ is longer than $\mathrm{AB}$ by activating their knowledge of squares such as diagonals of a square is longer than its side. Q3 requires both manipulations and reasoning as described above (e.g. to draw the line DB, deduce that triangle $\mathrm{BDE}$ is an equilateral triangle, and then conclude that angle BED is 60 degrees). For each item we used oblique parallel projections as this would require students to activate their capabilities not only to reason based on given information but also to manipulate representations to reach their conclusions. Figure 4 shows the items we used.

Q1 In a cube, find the size of angle $\mathrm{ABC}$ in each case.
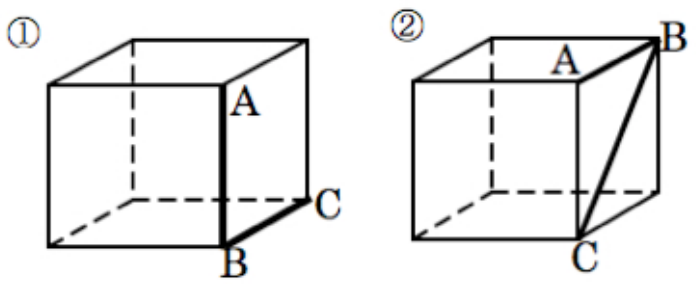

Q2 In a cube, which is longer, AB or CD? Choose your answers from a)-d) for each case.
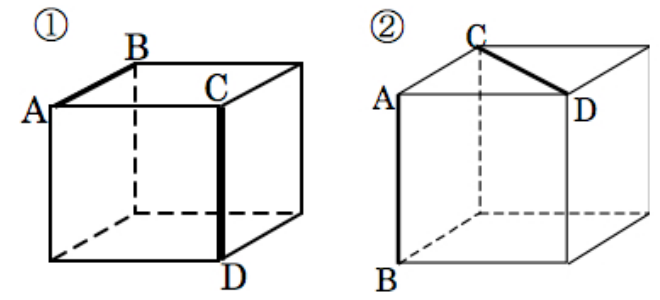
a) $\mathrm{AB}$ is longer
b) $\mathrm{CD}$ is longer
c) $\mathrm{AB}=\mathrm{CD}$
d) I am not sure which is longer.

Q3 From B and D of a cube, draw straight lines to E. What is the size of the angle BED? Also state your reason why.

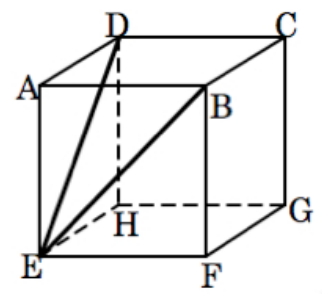

Figure 4: Assessment questions

We acknowledge that our assessment includes only five questions and that the only geometric shape represented among them is a cube, but these questions do not appear in Japanese textbooks which mainly provide learning contents for names of 3D shapes, 
nets, sections of cube, surface areas and volume. By using problems in unfamiliar situations, we hypothesised that we would be able to assess geometric thinking beyond that which is typically elicited in conventional lessons. We also acknowledge the limitation our assessment: although a cube is a canonical geometric shape, a limitation of the framework is that it does not span greater range of geometric shapes.

\subsection{Participants}

In order to investigate a considerable path of 3D thinking, we implemented an assessment in four junior high schools in Japan: 145 G7, 157 G8 and 153 G9, in total 455 students between February and March 2015. All four schools are recognised as ordinary local schools in Japan, i.e. there is a range of student ability within them. The assessment questions were posed only after all students had studied the required content of the geometry curriculum as described in section 3.1.

\section{Results}

Our preliminary assumptions are as follows: Q1 and Q2 are rather straightforward questions in that their solutions follow from the properties of a cube without the extensive need for manipulation and without much breadth of logical inference. Performing poorly on these items would indicate such students might be influenced by the visual information of the representations in terms of their appearance alone as 2D shapes. If a student answers items Q1 and Q2 correctly, then her/his understanding will be examined further by Q3, for which we expect both reasoning and manipulations would be involved in order to answer correctly.

Tables 2, 3, 4 and 5 summarise the overall results of from 455 students (\%s, 145 G7, 157 G8 and 153 G9 in total 455 students). The first question asks students to judge the size of the angle in a cube, and as we expect, almost all students answered this question correctly. The students did well for Q2-(1) but G7 and G8 students had difficulties answering Q2-(2). This might be because this question requires students to manipulate the representation either mentally or by drawing to see relevant lengths more clearly. Also G9 students did well, probably because they had studied the Pythagorean Theorem and this helped them determine the length of CD. Consistent with our findings in the pilot assessment with 570 students, all the students had difficulties with item Q3 with the identified the five categories (see Section 2.3), i.e. (A1) no answer, (A2) incorrect answer led by 2-dimensional or intuitive global judgment; (A3) incorrect answer led by intuitive knowledge and visual information; (B) incorrect answer with some manipulations of a cube but influenced by visual information; (C) incorrect answer by using sections of cube but influenced by intuitive knowledge and visual information; and (D) correct answer with valid reasoning. G9 students performed better and again this may be due to their learning of the 
Pythagorean Theorem.

Table 2: Q1 results

\begin{tabular}{|l|l|l|l|l|}
\hline \multirow{3}{*}{ Q1 } & \multicolumn{2}{|l|}{ 1) \% answers } & \multicolumn{2}{l|}{ (2) \% answers } \\
\cline { 2 - 5 } & $90^{\circ}$ Correct & Other answers & $45^{\circ}$ Correct & Other answers \\
\hline G7 & 87 & 14 & 80 & 20 \\
\hline G8 & 90 & 10 & 89 & 11 \\
\hline G9 & 97 & 3 & 95 & 5 \\
\hline
\end{tabular}

Table 3: Q2-(1) results

\begin{tabular}{|l|l|l|l|l|l|}
\hline $\begin{array}{l}\text { Q2-(1) } \\
(\%)\end{array}$ & a) & b) & c) Correct & d) & No answer \\
\hline G7 & 1 & 3 & 96 & 0 & 0 \\
\hline G8 & 1 & 6 & 91 & 2 & 0 \\
\hline G9 & 0 & 1 & 96 & 3 & 0 \\
\hline
\end{tabular}

Table 4: Q2-(2) results

\begin{tabular}{|l|l|l|l|l|l|}
\hline $\begin{array}{l}\text { Q2-(2) } \\
(\%)\end{array}$ & a) & b) Correct & c) & d) & No answer \\
\hline G7 & 10 & 58 & 30 & 2 & 1 \\
\hline G8 & 13 & 55 & 29 & 4 & 0 \\
\hline G9 & 7 & 86 & 5 & 1 & 1 \\
\hline
\end{tabular}

Table 5: Q3 results

\begin{tabular}{|l|l|l|l|l|l|l|}
\hline Q3 (\%) & $\begin{array}{l}\text { Type of } \\
\text { error: A1 }\end{array}$ & $\begin{array}{l}\text { Type of } \\
\text { error: A2 }\end{array}$ & $\begin{array}{l}\text { Type of } \\
\text { error: A3 }\end{array}$ & $\begin{array}{l}\text { Type of } \\
\text { error: B }\end{array}$ & $\begin{array}{l}\text { Type of } \\
\text { error: C }\end{array}$ & $\begin{array}{l}\text { Correct } \\
\text { answer: D } \\
60 \\
\text { degrees) }\end{array}$ \\
\hline G7 & 17 & 15 & 55 & 10 & 2 & 1 \\
\hline G8 & 23 & 15 & 39 & 15 & 3 & 4 \\
\hline G9 & 19 & 8 & 20 & 22 & 7 & 24 \\
\hline
\end{tabular}


We also examined the relationships between Q2-(2), and Q3; see Tables 6, 7, and 8. While many of the students who answered Q2-(2) correctly answered Q3 incorrectly (with all types of errors), almost all the students who could answer Q3 correctly could answer Q2-(2) correctly. These tables suggest the hierarchical relationship between Q2-(2) and Q3 (with Q3 being higher), despite the overall percentage of those who succeeded in Q3 being low. We return to the latter point further below.

Table 6: Relationship between Q2-(2) and Q3, G7

\begin{tabular}{|l|l|l|l|l|l|l|}
\hline $\begin{array}{c}\text { Answers } \\
\text { to } \\
\text { Q2-(2)/ } \\
\text { Q3 }\end{array}$ & A1 & A2 & A3 & B & C & D Correct \\
\hline a) & 4 & 2 & 7 & 1 & 0 & 0 \\
\hline b) Correct & 12 & 11 & 48 & 10 & 2 & 1 \\
\hline c) & 9 & 7 & 23 & 3 & 1 & 0 \\
\hline d) & 0 & 2 & 1 & 0 & 0 & 0 \\
\hline No answer & 0 & 0 & 1 & 0 & 0 & 0 \\
\hline
\end{tabular}

Table 7: Relationship between Q2-(2) and Q3, G8

\begin{tabular}{|l|l|l|l|l|l|l|}
\hline $\begin{array}{c}\text { Answers } \\
\text { to } \\
\text { Q2-(2) } \\
\text { Q3 }\end{array}$ & A1 & A2 & A3 & B & C & D Correct \\
\hline a) & 9 & 4 & 6 & 1 & 0 & 0 \\
\hline b) Correct & 13 & 12 & 38 & 16 & 2 & 5 \\
\hline c) & 12 & 7 & 18 & 5 & 3 & 1 \\
\hline d) & 2 & 1 & 2 & 1 & 0 & 0 \\
\hline No answer & 0 & 0 & 0 & 0 & 0 & 0 \\
\hline
\end{tabular}

Table 8: Relationship between Q2-(2) and Q3, G9

\begin{tabular}{|l|l|l|l|l|l|l|}
\hline $\begin{array}{l}\text { Answers } \\
\text { to } \\
\text { Q2-(2/ } \\
\text { Q3 }\end{array}$ & A1 & A2 & A3 & B & C & D Correct \\
\hline a) & 2 & 1 & 1 & 3 & 1 & 2 \\
\hline
\end{tabular}




\begin{tabular}{|l|l|l|l|l|l|l|}
\hline b) Correct & 22 & 8 & 26 & 31 & 10 & 35 \\
\hline c) & 4 & 2 & 1 & 0 & 0 & 0 \\
\hline d) & 0 & 0 & 2 & 0 & 0 & 0 \\
\hline No answer & 1 & 1 & 0 & 0 & 0 & 0 \\
\hline
\end{tabular}

In order to see the overall relationships between the five questions in terms of their difficulties, we first produced a $455 \times 5$ matrix with $($ Not correct, Correct) $=(0,1)$ variables and conducted the Rasch model analysis with $R 3.3 .1$ with the package ' $1 \mathrm{tm}$ ' ver. 1.0 (produced by Dimitris Rizopoulos in 2013) which enables us to conduct the latent trait models under the Item Response Theory approach. The calculated coefficients for difficulties are summarised in the table 9 below:

Table 9: coefficients for difficulties for Q1-3

\begin{tabular}{|l|l|l|l|}
\hline Assessment question & Difficulty values & Std. Error & $\begin{array}{l}95 \% \text { confidence } \\
\text { intervals }\end{array}$ \\
\hline Q1-(1) & -1.8451 & 0.1442 & $-2.1277 \sim-1.5625$ \\
\hline Q1-(2) & -1.5526 & 0.1248 & $-1.7972 \sim-1.3080$ \\
\hline Q2-(1) & -2.1227 & 0.1662 & $-2.4383 \sim-1.7869$ \\
\hline Q2-(2) & -0.5483 & 0.0827 & $-0.7104 \sim-0.3862$ \\
\hline Q3 & 1.7222 & 0.1329 & $1.4617 \sim 1.9827$ \\
\hline
\end{tabular}

Also the following item characteristic curves are drawn from the above data (note that in figure 5, Q1-(1) is represented as Q11 and so on). 


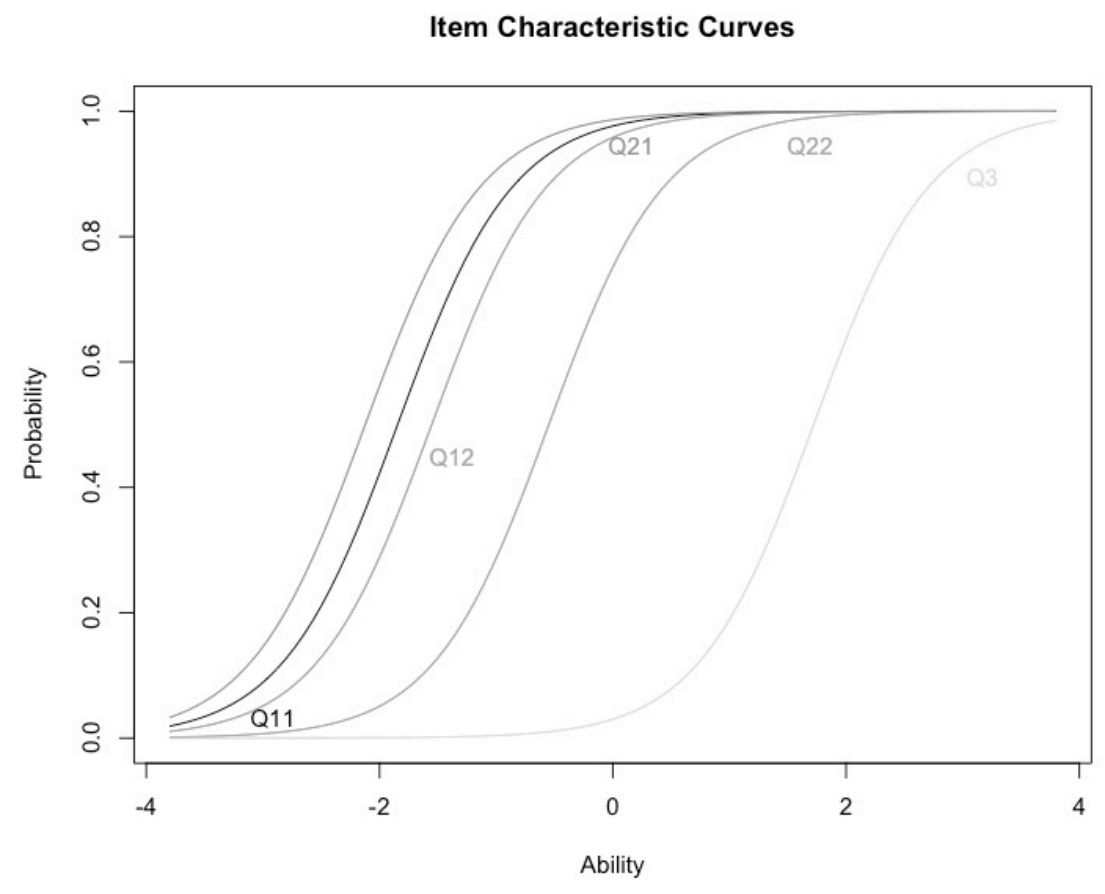

Figure 5 Item Characteristic curve for Q1-3.

What the table 9 and Figure 5 imply is as follows. Suppose in the population group the average ability is 0 , and -4 as least ability and 4 as best. The difficulty values suggest that for example even a student with ability of -1.8 has $50 \%$ chance for answering correctly for Q1-1), suggesting this question is very easy. On the other hand, even a student with 1.7 ability has $50 \%$ of chance for answering correctly for Q3, suggesting this question is very hard in this population group. Also, the first three questions' 95\% confidence intervals are almost overlapping, but Q2-(2) is separated, and Q3 is separated again. These as a whole suggest that that the three difficulties for assessment questions in our sample of 455 students, i.e. $\{(\mathrm{Q} 1-(1), \mathrm{Q} 1-(2), \mathrm{Q} 2-(1)),(\mathrm{Q} 2-(2)),(\mathrm{Q})\}$. Also, it is clear that there is a rather big gap between Q2-(2) and Q3, and this is indeed consistent with our findings of various types of errors in Q3, identified as (A1) no answer, (A2) incorrect answer led by 2-dimensional or intuitive global judgment; (A3) incorrect answer led by intuitive knowledge and visual information; (B) incorrect answer with some manipulations of a cube but influenced by visual information; (C) incorrect answer by using sections of cube but influenced by intuitive knowledge and visual information.

\section{Assessment framework for geometrical thinking with cube representations}

The results from 455 students suggest that for even a set of simple assessment questions students demonstrated a greater range of different (and interesting) answers that are suitable for categorisation. In particular the following two points are informative for constructing an assessment framework: a) students' difficulties are 
categorised in terms of their performance of $\{(\mathrm{Q} 1-(1), \mathrm{Q} 1-(2), \mathrm{Q} 2-(1)),(\mathrm{Q} 2-(2)),(\mathrm{Q})\}$, b) there are various forms of thinking observed between Q2-(2) and Q3, exemplified as $\mathrm{A} 1, \mathrm{~A} 2, \mathrm{~A} 3, \mathrm{~B}, \mathrm{C}$ and D (see Section 2.3) and c) thinking is classified in terms of manipulations and reasoning. We take manipulations as students' interactions with both physical and mental representations, e.g. drawing lines, nets, cube from different orientations, applying measurement apparatuses, etc. By considering these points, we propose our assessment framework (table 10 and figure 6) consisting of seven categories as a way to assess students' geometrical thinking when they undertake cube problems. Next, we take geometric reasoning to mean the use of geometric properties and other information in problem solving. For example, for type A2, and 3 it is difficult to assess their reasoning based on properties of shapes because they judged the size of angle from visual information directly. For B, their reasoning may be correct, but the activated manipulations lend themselves to misinterpretations. For example, drawing the net and deducing 90 degrees is correct itself, but with this manipulation it is impossible to find the size BED. For C, by manipulation, triangle BED is identified but influence from visual aspects of the representation do not allow for the recognition of the triangle as equilateral, and, as a result, the problem solver is likely to make an invalid deduction. By proposing this framework we provide our answer to the RQ1 'What assessment framework can be constructed to assess students' geometric thinking when they are solving $3 \mathrm{D}$ geometry problems with $2 \mathrm{D}$ representations?'

Table 10 Assessment framework for the results from 455 students

\begin{tabular}{|l|l|}
\hline Category & Assessment descriptors \\
\hline Category 0 & $\begin{array}{l}\text { Students who failed to answer all of the assessment questions. } \\
\text { These students might not recognise given representations as 3D } \\
\text { geometric shapes. }\end{array}$ \\
\hline Category 1 & $\begin{array}{l}\text { Students who only answered correctly for the first set of three } \\
\text { questions Q1-(1), Q1-(2) \& Q2-(1), but failed to answer and } \\
\text { Q2-(2) and Q3. Failing to answer Q2-(2) means they have } \\
\text { difficulties finding the length of CD, suggesting weaker capacity } \\
\text { to manipulate to compare AB and CD, and therefore they do not } \\
\text { reason why CD is longer. As students in this category fail to } \\
\text { answer Q2-(2), Q3 was too difficult for these students. }\end{array}$ \\
\hline Category 2-A & $\begin{array}{l}\text { Students who answered correctly for the first set of four } \\
\text { questions, Q1-(1), Q1-(2) \& Q2-(1), and Q2-(2). This suggests that } \\
\text { students in this category can undertake simple manipulations, e.g. } \\
\text { mentally seeing CD as a diagonal of the face. For Q3, } \\
\text { students in this category made type A1, A2 or A3 errors, } \\
\text { indicating that their reasoning is influenced by only immediately } \\
\text { available visual information or intuitive judgement. }\end{array}$ \\
\hline
\end{tabular}




\begin{tabular}{|l|l|}
\hline Category 2-B & $\begin{array}{l}\text { In this category students answered Q1-(1), Q1-(2) \& Q2-(1), and } \\
\text { Q2-2) correctly but Q3 with type B error, suggesting that } \\
\text { students in this category attempted to manipulate with } \\
\text { representation, e.g. drawing a net, but this manipulation does not } \\
\text { lead the faulty reasoning that led to an incorrect for Q3. }\end{array}$ \\
\hline Category 2-C & $\begin{array}{l}\text { In this category students answered Q1-(1), Q1-(2) \& Q2-(1), and } \\
\text { Q2-2) correctly but Q3 with type C error. Manipulations such as } \\
\text { drawing a line DB and then detaching a triangle DEB is } \\
\text { activated, but their reasoning was informed by, for example, } \\
\text { seeing the triangle DEB as a right-angled triangle and deducing } \\
\text { from that observation that one if its angles measures 90 degrees. }\end{array}$ \\
\hline Category 3 & $\begin{array}{l}\text { Students who answered all the five questions correctly. Indicating } \\
\text { e.g. to draw the line DB, deduce that triangle BDE is an } \\
\text { equilateral triangle, and then conclude that angle BED is 60 } \\
\text { degrees. }\end{array}$ \\
\hline
\end{tabular}

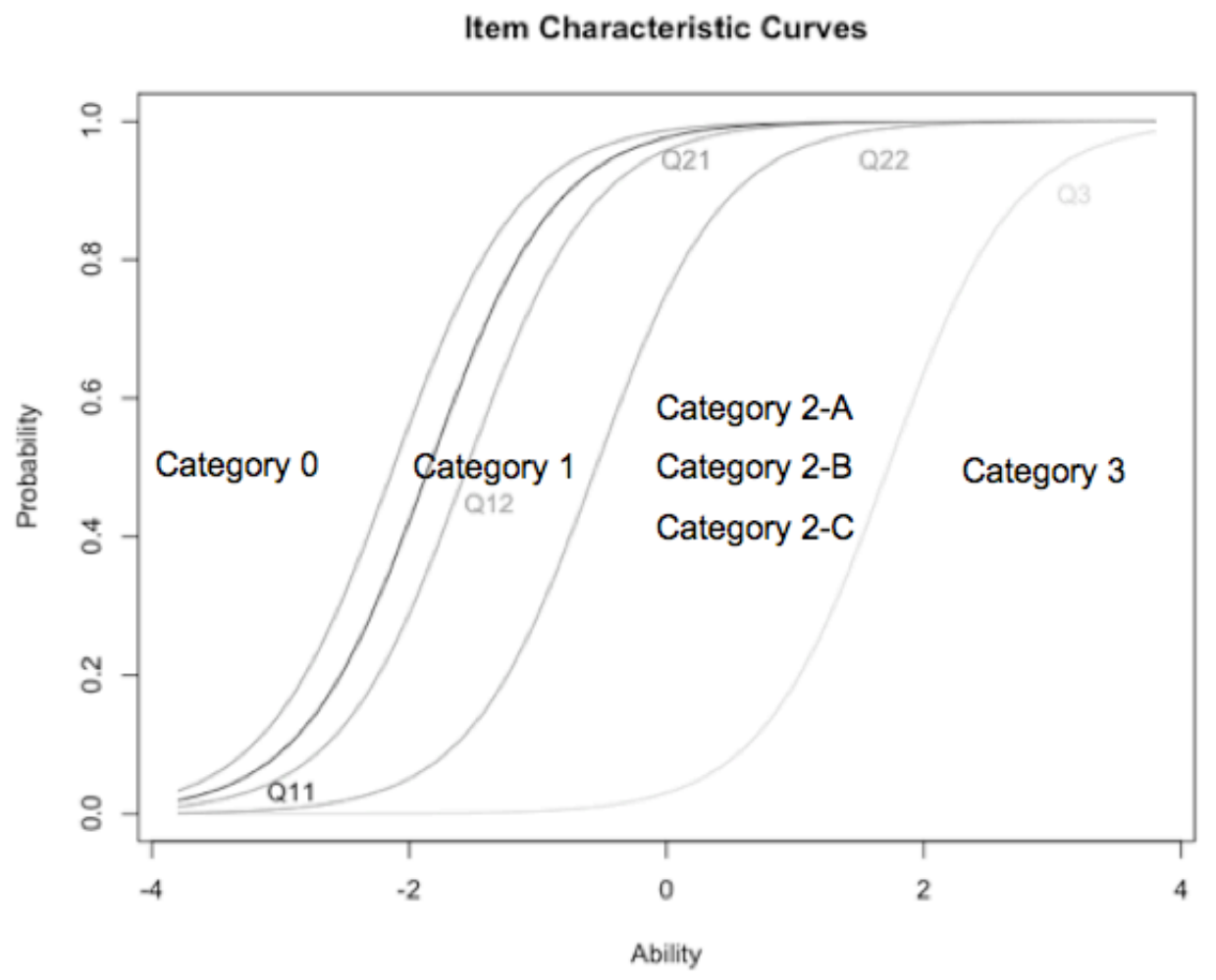

Figure 6: Assessment categories 
We now present how we can categorise the responses from the 455 students by considering their overall performance in terms of the descriptions above, summarised in Table 11. Our findings indicate that the majority of our sample students are assessed as either category 0,1 or $2-\mathrm{A}$ thinking with $3 \mathrm{D}$ shape representations. In category 2 there are more type-A than other types. The G9 students' result is better, but $24 \%$ in category 3 is still low.

Table 11: Distribution of students' 3D thinking

\begin{tabular}{|l|l|l|l|l|l|l|l|}
\hline Category(\%) & 0 & 1 & $2-\mathrm{A})$ & $2-\mathrm{B})$ & $2-\mathrm{C})$ & 3 & Not categorised \\
\hline G7 & 8.3 & 33.1 & 43.4 & 6.9 & 1.4 & 0.7 & 6.2 \\
\hline G8 & 8.3 & 36.3 & 38.2 & 10.8 & 1.3 & 3.8 & 1.3 \\
\hline G9 & 1.3 & 11.0 & 35.1 & 20.8 & 6.5 & 24.0 & 1.3 \\
\hline
\end{tabular}

For each grade, there are small numbers of students whose thinking is assessed to be 'Not categorised'. Not adequately being able to explain and understand these students' thinking is one of the limitations of our approach and we do not claim our assessment framework can fully explain everything about all students' geometric thinking as any model has its limitations (e.g. for van Hiele's model see Fuys et al. 1998; Lehrer et al. 1998; Clements, et al. 2001; Sinclair and Bruce, 2015). In particular our framework does not take any account of discursive aspects of geometrical thinking, which has been recognised as one of the important aspects of thinking (Sinclair, et al. 2016). We will discuss these limitations in the later part of this paper. Nevertheless, about $97 \%$ students' thinking in our sample can be categorised by our framework, which provides useful information for the teaching and learning of geometry with 3D representations.

Another issue is that we constructed our assessment framework from a set of structurally similar problems, and it is still unknown how our framework is applicable to other situations. In the next section, in order to address our RQ 2 'How can we apply this framework to understand various forms of students geometrical thinking in everyday lesson situations?', we further provide two cases of examples from our classroom-based studies.

6. Students' 3D thinking in classroom based studies

\subsection{Classroom-based study background}

We use data from the following two sets of lessons which were part of our larger-scale of study of the teaching and learning and learning of geometry (informed by Kumakura, et al., 2000):

- Lessons A two lessons (each 50 minutes) in which the students worked with the same Q3 but were presented with a different orientation to the one used in our assessment question (see figure 7); 
- Lessons B two lessons in which students were asked to construct a net and make the model including the face DPFQ, where P and Q are the mid-points of $\mathrm{AE}$ and CG respectively, illustrated in Figure 1 (that the points D, P, F and Q are on the same plane should be proved but this fact was tacitly assumed).

We refer to the above classroom-based data because such qualitative data can further complement our understanding of students' thinking. . In the Lessons A the cube in the problem uses the oblique parallel projection and the angle to be found is changed from the original assessment problem. All this means that it is not straightforward to know, for example, the size of angle BGD because of this representation (see Figure 7 below). We included Lessons B in order to see whether our framework can be applied to other problem situations which do not appear in our assessment questions, which is to reason about quadrilateral DMFN in Figure 1. To reason the shape is a rhombus, students need not only deduce the shape satisfies a definition of a rhombus, but also they need to tackle the problem effectively to elucidate some hidden relationships such as $\mathrm{DF}>\mathrm{MN}$.

For Lessons A, two 50 min lessons were taught by a teacher to a class of 28 Grade 7 students (aged 12-13) in a public school in Japan in 2012. The class teacher, Mrs M, has more than 20 years teaching experience, and is particularly interested in students' geometrical reasoning processes. Given that teachers' interactions with students are crucial to encourage students' reasoning (e.g. Jones and Herbst, 2012), in general her role in the lessons was to facilitate students' discussions by suggesting where to direct their attention in the problem, which properties might be used, and so on. Through following the Japanese geometry curriculum, the students had already studied selected properties of solid figures such as nets, sections of a cube, surface areas and volume (note that the measurement of the angle between two lines in 3D space is not formally studied within the prescribed curriculum). For Lessons B two 50 min lessons were jointly taught by Mrs M and one of the authors to a class of 28 Grade 8 students (aged 13-14) in the same school in 2011. For both lesson sets, field notes were kept and the audio was transcribed. In addition, student worksheets from both lessons were collected to obtain information on how the students' reasoning changed across the lessons.

All data were analysed qualitatively in terms of the categories of 3D thinking proposed above, i.e. we particularly analysed students' interactions with the teacher during the lessons and their answers and explanations in their worksheets. Through this we describe students' thinking in terms of our assessment framework by identifying their types of manipulations and reasoning with representations.

6.2. Lessons A: What is the size of the angle?

6.2.1 Overall lesson progressions 
In order to answer survey question Q3 (Figure 3) correctly students could deduce that triangle BGD is an equilateral triangle. During the two lessons of Case 1, the 25 students (3 students were absent during the first lesson) attempted to solve the problem with a different orientation as presented by the teacher, Mrs M. In the first lesson, after the problem was posed, the students began by tackling the problem individually. Their initial answers from their worksheets are shown in Table 12. As can be seen from the Table, only five of the students correctly answered that the angle measured $60^{\circ}$.

Table 12: Students' initial answers to the problem

\begin{tabular}{|c|c|c|c|c|c|c|c|}
\hline Answer & $90^{\circ}$ & $60^{\circ}$ & $22.5^{\circ}$ & $30^{\circ}$ & $45^{\circ}$ & $35^{\circ}$ & $90^{\circ}$ or $60^{\circ}$ \\
\hline Number of students & 8 & 5 & 4 & 2 & 2 & 1 & 2 \\
\hline
\end{tabular}

In total 24 answers; one student did not write any answer.

After this initial stage of working individually, the teacher asked the students to share their ideas and answers in groups, and then the teacher selected six different students to present their answers to the class (she observed these six different answers when she was observing students in their individual/group activities). The six answers in Figure 7 were presented.

\section{(1) $35^{\circ}$ (Student F1)}

I thought it is $35^{\circ}$ because I used a set square (to measure the angle in the representation), and it seems $10^{\circ}$ smaller.
(2) $45^{\circ}$ (student Y)

I used a net and if $I$ cut it from $B$ to $D$, then it is $45^{\circ}$. So $\angle \mathrm{BGD}=45^{\circ}$

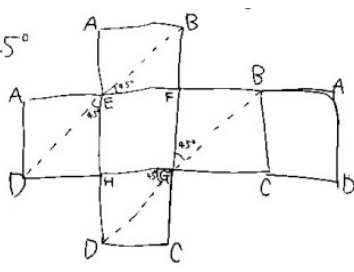

5) $22.5^{\circ}$ (Student K)

A line DG halves a square, and another line BG further halves it. So $90 \times 1 / 2=45$, and $45 \times 1 / 2=22.5$.

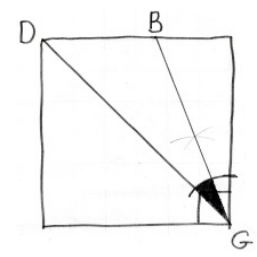

(3) $90^{\circ}$ (Student F2)

I rotated the cube and I can make an isosceles triangle BGD. And $\angle \mathrm{BGD}=90^{\circ}$

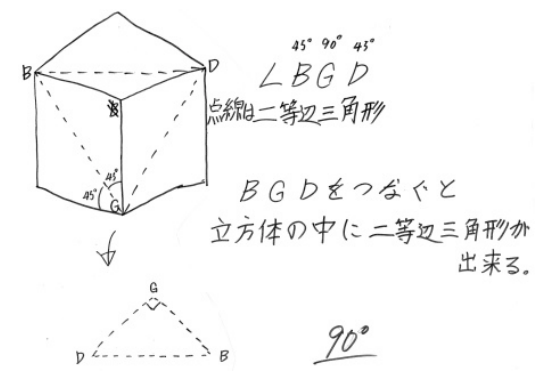

(6) $30^{\circ}$ (Student H)

No explanation and angles are measured as $2 \mathrm{D}$ angles.

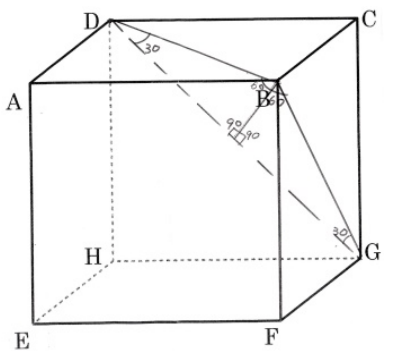


Figure 7: Presenting students' answers

At the start of the second lesson the 24 students (four were absent during the second lesson) continued to exchange their ideas and reasoning in groups. First, Mrs M asked the students whether they would change their answers or not, based on the six presentations of their fellow students at the end of the first lesson. The students' revised answers are shown in Table 12.

Table 12: Students' revised answers to the problem

\begin{tabular}{|c|c|c|c|c|c|c|c|}
\hline Answer & $90^{\circ}$ & $60^{\circ}$ & $22.5^{\circ}$ & $30^{\circ}$ & $45^{\circ}$ & $35^{\circ}$ & $22.5^{\circ}$ or $60^{\circ}$ \\
\hline Number of students & 6 & 16 & 0 & 1 & 0 & 0 & 1 \\
\hline
\end{tabular}

The number of students giving the answer $60^{\circ}$ had risen to 16 , which was recognised as an improvement by the teacher but she observed not all students who agreed with $60^{\circ}$ could explain why it would be $60^{\circ}$. Also, some students still argued why they did not recognise the angle as $60^{\circ}$. For example, a student who once changed his/her answer from $45^{\circ}$ to $60^{\circ}$ stated that $\angle \mathrm{BGC}$ and $\angle \mathrm{CGD}$ might be $45^{\circ}$. Mrs $\mathrm{M}$ asked the students to consider an explanation which would help everyone in the class to consider whether the answer was $60^{\circ}$. One student explained BGD is an equilateral triangle. Mrs $M$ then asked the students to further develop an explanation that would enable everyone to agree that the answer is $60^{\circ}$. Student IM proposed refuting $90^{\circ}$ by showing that it is impossible to have three $90^{\circ}$ angles in an equilateral triangle. This thinking is beyond what we would expect at grade 7 , since students in that grade have not yet learned to write formal proofs:

L2a-S24: Student IM (writing the following answer) The sum of the inner angles of a triangle is $180^{\circ}$ so $90^{\circ}$ does not work. $D=90^{\circ}, B=90^{\circ}$, $G=90^{\circ} . D+B+G=90^{\circ}+90^{\circ}+90^{\circ}=270^{\circ}$.

L2a-T29: Mrs M Can you explain this?

L2a-S25: Student IM If the line BD, DG and BG are all the same, then ... no, sorry. If you add the angles of a triangle, then $180^{\circ}$, and if $\angle \mathrm{BGD}$ is $90^{\circ}$, then it is an equilateral, so all angles should be the same and the other two angles are also $90^{\circ}$, and add them together it will be $270^{\circ}$. This does not work.

Mrs $M$ then used a physical model of a cube to demonstrate the reasoning. This completed the second lesson.

\subsubsection{Assessment of students' thinking with the framework}

The nature of the solutions given in Figure 7 indicates that their reasoning is likely to be categorised into the criteria discussed in Table 10. As might be expected, students in the class illustrated various forms for solving Q3. In the first lesson, some students 
determined the size of the angle neither by referring to the properties of 3D shapes nor by manipulating the presented figure. In our case, student F1 (the Figure 7-(1)) or H (in Figure 7-(6)) for example, used measurement from the given representation, and did not have any idea why this would not be correct. These students can be considered as at least Category 2-A or below in our assessment framework.

Meanwhile, some students demonstrated their capacities to use the properties of a cube and some manipulations. For example, student $\mathrm{K}$ in Figure 7-(5) 'extracted' a part of a cube (manipulation) and then reasoned the size of angles. Such thinking can be considered as Category 2-B, i.e. they utilised properties of shapes and started to manipulate the given representation, but their manipulations were influenced by the visual information, and did not activate useful properties for correct answers. Like student $\mathrm{Y}$ in Figure 7-(2), student $\mathrm{C}$ utilised a net to consider the size of the angle BGD to deduce the angle is $90^{\circ}$, as illustrated in Figure 8. As evident, this approach does not work because the angles in the net and the angle required in the problem are different. Yet this student did not see this by using only the net representation, i.e. they did not utilise the properties of cubes independently from the used representations, again classified as Category 2-B.

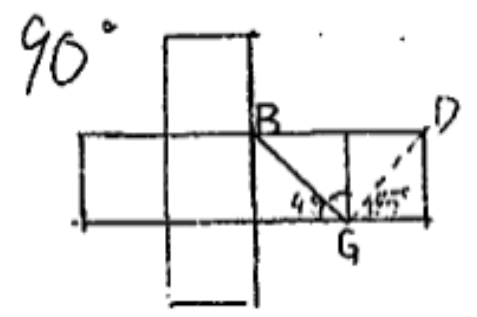

Figure 8: Answers by C

Other students used more manipulations of shapes and also started using properties of shapes to construct some deductions. In our study an example of this was when student F2 (Figure 7-(3)) joined B and D to form triangle BDG and started examining what the triangle BDG would be to deduce the size of the angle. However, the following exchange shows that this student did not recognise the triangle BGD as an equilateral because of how the representation of the cube looked:

L1a-S72: Student F2 I joined B and D.

L1a-T76: Mrs M Join B and D, and then?

L1a-S73: Student F2 Then I see a right-angled isosceles triangle (Figure 2-(3)).

L1a-T77: Mrs M OK, you thought the triangle is a right-angled isosceles triangle...

L1a-S74: Student F2 So, G should be $90^{\circ}$ ?

It is notable that student F2 changed the oblique parallel projection to an orthogonal projection (see Figure 7-(3)) as the result of the mental rotation of the representation. However F2's inferences from that rotation were incorrect.. F2's mental rotation can 
go in the right direction, but after drawing a new picture, F2 considered the triangle as a right-angled isosceles triangle (e.g. line L1a-S73) and this led to reason the angle would be 90 degree, categorised as Category 2-C.

Nevertheless, it was the case that even in the first lesson some students demonstrated their reasoning which was not overly influenced by the external representation of the cube but was more controlled by logical thinking and deductions from properties of the 3D shapes,demonstrating Category 3 thinking. For example, student IM explained his reasoning as follows:

L1a-S78: Student IM Because in a cube all diagonals should be the same length, this triangle is an equilateral.

L1a-T82: Mrs M OK, you thought it will be an equilateral because of the length of the diagonals.

L1a-S79: Student IM [nods] Each angle of an equilateral triangle is $60^{\circ}$, so $\angle B D G$ is $60^{\circ}$.

\subsection{Lessons B: Let us make a model of the shape!}

\subsubsection{Overall lesson progressions}

In the Lessons B, as described in Section 5.1, the students were not only expected to identify the face DMFN (Figure 1 in this paper), but also to construct an actual net and make a model of it. This additional practical requirement is a particularly important learning opportunity in these lessons as we consider this is more likely to create perturbations (such as the square DMFN does not fit) which for many students leads them to finding the solution more easily than a question that solely asks students to determine the shape of the face DMFN. In the latter case, students might say that the face is a square, and it might be more difficult for them to recognise that it is not a square without physically creating the model. Also, when students engage with physical models, geometrical thinking can still be observed by examining the verbal articulations and their interactions with the model. This was indeed observed in our case presented below. In the lesson, after the problem was introduced, students started making a model individually and then exchanged their ideas in a small in a small group, which allowed us to observe their thinking through recording their verbal communications when interacting with physical models. Towards the end of the second lesson Mrs M discussed what shape DMFN was through whole class interactions.

\subsubsection{Assessment of students' thinking with the framework}

In these lessons, a range of different forms of thinking was observed and characterised by our assessment framework. For example, the following conversations by two students indicate their thinking is likely to be Category 2-A, as one of the students 
(L1-S43: Student C) reasoned only by looking at the diagram, and the other student agreed with this idea (L1-S44: Student D).

L1b-S40: Student D So, if we put this square to the edges by force, then it would not fit. Look, the angles look different (to 90 degree).

L1b-S41: Student C You are saying this is not a square? But if you see the diagram which was given to us, it is a square?

L1b-S42: Student D Really?

L1b-S43: Student C We do not know the size of angle from the diagram, but all the sizes are the same so it should be a square.

L1b-S44: Student D OK, then we can just cut a bit of the shape (DMFN), and then... Does this work?

Also, some students cut the face DMFN by placing the model directly on the paper (Figure 9). This manipulation did suggest to students that the angle might not be 90 degree but students who used this approach did not reason why the shape is a non-square rhombus, and we thus consider this is similar to thinking in Category 2-B as this physical manipulation did not activate thinking around the properties of shapes to expand their reasoning. .
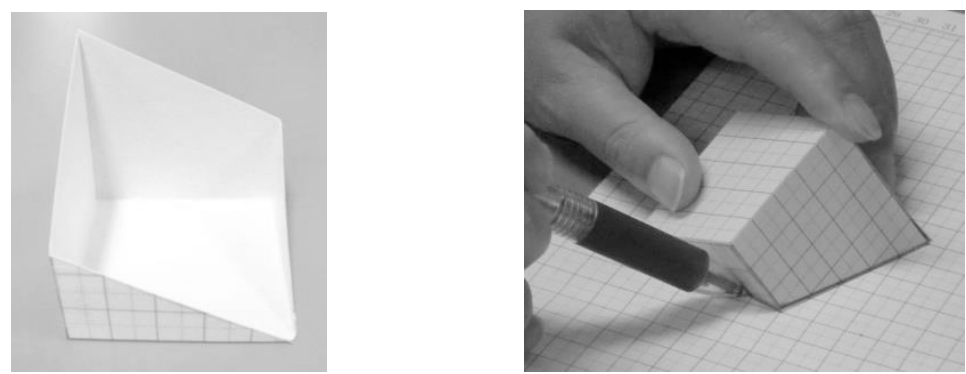

Figure 9: Cutting the face directly

At the end of the first lesson students started noticing the shape is not square but did not decide and reason why it is a non-square rhombus. Many students drew diagonals of DMFN on the given diagrams, and this manipulation could have been used for deducing what shape DMFN might be, but they could not reason why further, therefore such thinking is judged as Category 2-C.

In the second lesson, with the teacher's instructional intervention, some students managed to explain why DMFN is a non-square rhombus and not a square by looking at the lengths of DF and MN. After interactions with the class teacher, finally a student (MF) could explain why the shape is not a square.

L2b-T24: Mrs M So do you think the length of MN is equal to a diagonal AC?

L2b-20: Student MF Yes, equal.

L2b-T25: Mrs M Why? 
L2b-21: Student MF They look equal, parallel lines.

\section{L2b-T26: Mrs M AMNC, what quadrilateral is it?}

L2b-22: Student MF Rectangle.

L2b-T27: Mrs M OK, if you dissect this cube along AC to bottom, where will we reach?

L2b-23: Student MF EG

\section{L2b-T28: Mrs M OK, and now, what is AEGC?}

L2b-24: Student MF Rectangle.

L2b-T29: Mrs M And what is AMNC, which is the half of AEGC?

L2b-25: Student MF Rectangle (Figure 10 left)

L2b-T30: Mrs M OK? So let us continue, student MF.

L2b-26: Student MF If we cut along DB to HF, then DHFB is a rectangle, and the diagonal is DF (Figure 10 right), so the length of DF is different from $\mathrm{MN}$ (as $\mathrm{MN}=\mathrm{AC}$, and therefore $\mathrm{DFMN}$ is not a square).
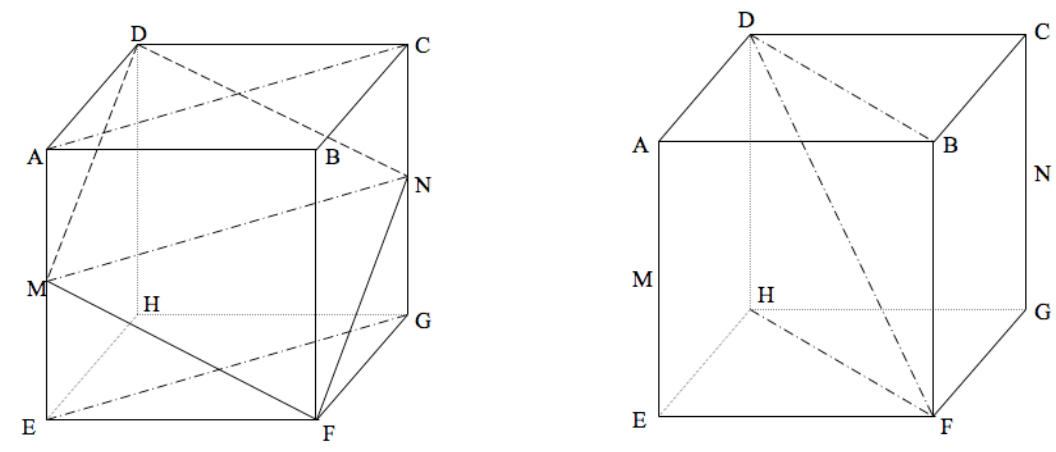

Figure 10: MF's reasoning

Here MF reasoned why MN is not equal to DF by using the properties of rectangle. We consider this as Category 3 thinking as MF not only (mentally) manipulated the given representation effectively but also used the properties well in order to deduce $\mathrm{DF}>\mathrm{MN}$, and refute DMFN would be a square

In summary, by using the preliminary category presented in Table 10 and the observed students' problem solving processes described above, their thinking can be categorised as follows (with the caveat that the type of thinking might depend on the problem).

Table 13: Categorised students' thinking for the Lessons B

\begin{tabular}{|l|l|}
\hline Category & Assessment descriptors \\
\hline Category 0 & $\begin{array}{l}\text { Students in this category cannot explore thinking with 3D shape } \\
\text { with representation. As the lesson used physical model, it was not } \\
\text { observed in the lessons B. }\end{array}$ \\
\hline
\end{tabular}




\begin{tabular}{|l|l|}
\hline Category 1 & $\begin{array}{l}\text { Students in this category consider that DMFN is a trapezium } \\
\text { including physically creating a trapezium with paper (by } \\
\text { perceiving the shape as 2D without mentioning any properties of } \\
\text { shapes. This was not observed in this experimental lesson but } \\
\text { observed other lessons). }\end{array}$ \\
\hline Category 2-A & $\begin{array}{l}\text { Students in this category consider that DMFN is a square without } \\
\text { stating any reasoning with given information in the representation. } \\
\text { When they use physical models, they often attempt to fit the square } \\
\text { by force, considering, for example, "because of measurement } \\
\text { errors it does not fit" (e.g. Students C and D). }\end{array}$ \\
\hline Category 2-B & $\begin{array}{l}\text { Students in this category attempted to manipulate the } \\
\text { representation, e.g. placing the model directly on the paper, but } \\
\text { this manipulation does not lead to to reason what DMFN is (such } \\
\text { as the example shown in Figure 9). }\end{array}$ \\
\hline Category 2-C & $\begin{array}{l}\text { Students in this category manipulate the representations such as } \\
\text { drawing diagonals in the given 2D representation and this can be } \\
\text { used for deducing the correct answer but still did not reason why } \\
\text { DMFN is not a square. }\end{array}$ \\
\hline Category 3 & $\begin{array}{l}\text { Students in this category can manipulate the representations } \\
\text { effectively and as a result they reason correctly why DMFN is a } \\
\text { rhombus (such as Student MF) }\end{array}$ \\
\hline
\end{tabular}

\section{A modified assessment framework based on the two case studies}

In terms of our research question 2 "How can we apply this framework to understand various forms of students geometrical thinking in everyday lesson situations?", from what we have observed in the four lessons that we studied, including in the students' worksheets, it is possible for us to characterise students' 3D thinking with our assessment framework. A similar tendency was also recognised in the Lessons B. Based on our preliminary assessment framework and observations from the Lessons A and $\mathrm{B}$, we suggest that our assessment framework be summarised, in more general term than those in tables 10 and 13, as follows.

Table 14: Assessment framework for 3D geometric thinking with representations

\begin{tabular}{|l|l|}
\hline Category & Assessment descriptors \\
\hline Category 0 & No capacity to manipulate or reason with 3D representations \\
\hline Category 1 & $\begin{array}{l}\text { Limited capacity to undertake simple manipulations with 3D } \\
\text { representations mentally seeing CD as a diagonal of the face, } \\
\text { resulting in difficulties to activate their knowledge to reason for } \\
\text { even simpler questions e.g. Q2-(2). }\end{array}$ \\
\hline Category 2-A & $\begin{array}{l}\text { Capacity to undertake relatively simple manipulations with 3D } \\
\text { representations, enabling students to answer correctly for Q2-(2) } \\
\text { For complex problems such as Q3 or lessons B, there are no } \\
\text { manipulations but some flawed deduction based on visual }\end{array}$ \\
\hline
\end{tabular}




\begin{tabular}{|l|l|}
\hline Category 2-B & $\begin{array}{l}\text { appearances in the given representations. } \\
\text { Capacity to undertake relatively simple manipulations with 3D } \\
\text { representations, enabling students to answer correctly for Q2-(2) } \\
\text { manipulations, drawing/adding to figures (e.g. adding extra lines, } \\
\text { drawing a net etc.), but such manipulations do not activate their } \\
\text { knowledge that can be used to deduce a correct answer for } \\
\text { given problems. }\end{array}$ \\
\hline Category 2-C & $\begin{array}{l}\text { Capacity to undertake relatively simple manipulations with 3D } \\
\text { representations. For more complex problems, students are } \\
\text { capable of undertaking manipulation or addition to the figure } \\
\text { which can be used to activate their knowledge in properties } \\
\text { which are useful to generate the correct answers, but they } \\
\text { cannot proceed further with their reasoning. This is due to, for } \\
\text { example, influences by ways they visualise geometric shapes from } \\
\text { the given representations (e.g. seeing a detached triangle as a right } \\
\text { angled triangle). }\end{array}$ \\
\hline Category 3 & $\begin{array}{l}\text { Capacity to manipulate the representation and demonstrate } \\
\text { valid reasoning by using properties of geometrical figures, } \\
\text { resulting in correct answers to complex problems such as Q3 or } \\
\text { lessons B }\end{array}$ \\
\hline
\end{tabular}

Reflecting on the above assessment, we can return to the classroom episode captured in Figure 1 at the beginning of the paper. The student in this classroom episode made no effective manipulations, and thus demonstrated flawed deduction based on visual appearance, i.e. how the triangle 'looks'. As such, according to our assessment framework this student's thinking is categorised as 2-A or below.

\section{Conclusion}

The intention of this paper is to propose a framework for 3D geometrical thinking. In this paper, we investigated students' problem solving with 3D shape representations. We first examined the nature of representations of geometrical figures by referring to Bishop (1983), Fischbein (1993) and Mesquita (1998), and suggested that an external representation may become an 'obstacle' to student understanding. Based on the existing studies (van Nes and van Eerde, 2010; Pittalis and Christou, 2010; 2013) and our own empirical data, we then developed an assessment framework of geometrical thinking that can be used to capture students' thinking with challenging problems involving 3D shape representations. In conclusion it is sobering to reflect on the words of Freudenthal (1971, pp. 417-418) "The deductive structure of traditional geometry has never been a convincing didactical success... It failed because its deductivity could not be reinvented by the learner but only imposed". As this observation by 
Freudenthal suggests, students' learning processes, and teachers' teaching approaches, in thinking with 3D representations are neither simple nor straightforward.

Meanwhile, we have made a small step towards better understanding of students' 3D geometrical thinking by providing the assessment category summarised in Table 14. In doing so, new questions have arisen during our research. For example, we found different types of thinking, but what are relationships between these forms of thinking? Are they hierarchical relationships between them or not? Which manipulations are more difficult than the others? In order to answer such questions, we need to devise more assessment questions which are likely to be more difficult than Q2-(2) but less difficult or similar to Q3 so that we can study students' thinking in this range of the difficulty more closely.

In our classroom episodes, it was useful when students in the class shared their ideas about various manipulations of shapes, reasoning and so on. In particular, student IM (Lessons A) or MF (Lessons B)'s refutations, which were each valid use of reasoning with properties, were recognised as a highlight of the lessons. Also it was important to allow students to think freely and follow this with small group discussion and then whole class discussion; an approach that might be particularly effective for promoting student thinking (see e.g. Yackel, et al, 1991; Boaler, 2016). This echoes what Fischbein (1987, p. 41) characterises as a "productive reasoning process". In the case studies we also could observe towards the end of the lessons students' visual thinking was challenged by the following lesson progression: The problem is first introduced, and then students share various ideas to investigate their ideas; Students were given opportunities to reason their answer, to share their reasoning and to modify their initial thinking; A correct answer was further confirmed by refuting answers which were visually influenced by the given representations. We are not in a position to claim that one or two lessons which follow the above progression will make significant changes to students' 3D geometrical thinking but we suggest that if lessons with such progressions are regularly implemented, then students' $3 \mathrm{D}$ geometrical thinking might be better developed. This of course needs further investigation to confirm this hypothesis.

Finally, we have not yet examined in detail what learning units that encourage "productive reasoning process" (Fischbein, 1987, p. 41) can be designed, how such units or lessons are effective to promote geometrical thinking and how mathematics teachers' instructional interventions impact students' learning. For example how can teachers support students' manipulations and interpretations of 3D shapes? And how can teachers help students check their interpretations of given representations of geometric figures and then make better use of them in their problem solving (i.e., move beyond 2-B thinking)? As Hiebert and Grouws (2007) explain in their comprehensive review, there remains much to learn about the inter-relationships between teachers' practices and students' learning. Indeed, according to Hiebert and Grouws, robust theories of teachers' instructional practices do not, as yet, exist. Thus, 
one of our future tasks is to work with issues such as the influence of different teaching instructions by teachers on students' decision-making, conjecture-production, and proof construction processes.

\section{Acknowledgement}

We are grateful to Keith Jones (University of Southampton, UK) for his support of theearlier version of the paper. We also thank the editors and the anonymous reviewers for their very helpful and critical comments on earlier versions of this paper.

\section{References}

Battista, M.T. (2007). The development of geometric and spatial thinking. In F. Lester (Ed.), Second Handbook of Research on Mathematics Teaching and Learning (pp. 843-908). Charlotte, NC: NCTM/Information Age Publishing.

Ben-Chaim, D., Lappan, G., \& Houang, R. T. (1989). Adolescents' ability to communicate spatial information: Analyzing and effecting students' performance. Educational Studies in Mathematics, 20(2), 121-146.

Bishop, A.J. (1983). Space and geometry. In R. Lesh \& M. Landau (Eds.), Acquisition of Mathematical Concepts and Processes (pp. 173-203) Orlando, Flo: Academic Press.

Boaler, J. (2016). Designing mathematics classes to promote equity and engagement. The Journal of Mathematical Behavior, 41, 172-178.

Fischbein, E. (1987). Intuition in Science and Mathematics: An educational approach. Dordrecht: Reidel.

Fischbein, E. (1993). The theory of figural concepts. Educational Studies in Mathematics, 24(2), $139-62$.

Freudenthal, H. (1971). Geometry between the devil and the deep sea. Educational Studies in Mathematics, 3(3\&4), 413-435.

Fujita, T. (2012). Learners' level of understanding of the inclusion relations of quadrilaterals and prototype phenomenon. The Journal of Mathematical Behavior, 31(1), 60-72.

Fuys, D., Geddes, D., \& Tischler, R. (1988). The van Hiele model of thinking in geometry among adolescents. Journal for Research in Mathematics Education. Monograph, i-196.

Godfrey, C. (1910). The Board of Education circular on the teaching of geometry. Mathematical Gazette, V, 195-200.

Hershkowitz, R. (1990). Psychological aspects of learning geometry. In P. Nesher \& J. Kilpatrick (Eds.), Mathematics and Cognition (pp. 70-95). Cambridge: CUP.

Hiebert, J., \& Grouws, D.A. (2007). The effects of classroom mathematics teaching on students' learning. In F.K. Lester (Ed.), Second Handbook of Research on Mathematics Teaching and Learning (pp. 371- 404). Charlotte, NC: Information Age Publishing.

Huang, W., Eades, P., \& Hong, S. H. (2009). Measuring effectiveness of graph visualizations: A cognitive load perspective. Information Visualization, 8(3), 139-152. 
Jones, K., \& Herbst, P. (2012). Proof, proving, and teacher-student interaction: Theories and contexts. In G. Hanna \& M. de Villiers (Eds.), Proof and Proving in Mathematics Education: the 19th ICMI Study (chapter 11). New York: Springer.

Küchemann, D., \& Hoyles, C. (2006). Influences on students' mathematical reasoning and patterns in its development: insights from a longitudinal study with particular reference to geometry. International Journal of Science and Mathematics Education, 4(4), 581-608.

Kumakura, H. Kubo, Y., Hatta, H. and Kunimune, S. (2000). The study of understanding of spatial geometry, Proceeding of $33^{\text {rd }}$ Annual conference of Japan Society of Mathematical Education, pp. 319-24 [in Japanese]

Jones, K., Fujita, T., \& Kunimune, S. (2012). Representations and reasoning in 3-D geometry in lower secondary school. In T-Y Tso (Ed.), Proceedings of the PME36 (Vol. 2, pp. 339-346). Taipei.

Lehrer, R., Jenkins, M., \& Osana, H. (1998). Longitudinal study of children's reasoning about space and geometry. In R. Lehrer \& D. Chazan (Eds.), Designing learning environments for developing understanding of geometry and space, (pp. 137-167). Mahwah, NJ: Erlbaum.

Mesquita, A. L. (1998). On conceptual obstacles linked with external representations in geometry, The Journal of Mathematical Behavior, 17(2), 183-195.

Mithalal, J. (2009). 3D geometry and learning of mathematical reasoning. In V. Durand-Guerrier, S. Soury-Lavergne, \& F. Arzarello (Eds.), Proceedings of CERME6 (pp. 796-805). Lyon, France: INRP.

Parzysz, B. (1988). 'Knowing' vs. 'seeing': problems of the plane representation of space geometry figures, Educational Studies in Mathematics, 19(1), 79-92.

Parzysz, B. (1991). Representation of space and students' conceptions at high school Level. Educational Studies in Mathematics, 22(6), 575-593.

Pittalis, M., \& Christou, C. (2010). Types of reasoning in 3D geometry thinking and their relation with spatial ability. Educational Studies in Mathematics, 75(2), 191-212.

Pittalis, M., \& Christou, C. (2013). Coding and decoding representations of 3D shapes. The Journal of Mathematical Behavior, 32(3), 673-689.

Royal Society (2001). Teaching and Learning Geometry 11-19. London, Royal Society/Joint Mathematical Council.

Sinclair, N., \& Bruce, C. D. (2015). New opportunities in geometry education at the primary school. ZDM, 47(3), 319-329.

Sinclair, N., Bartolini Bussi, M. G., de Villiers, M., Jones, K., Kortenkamp, U., Leung, A., \& Owens, K. (2016). Recent research on geometry education: An ICME-13 survey team report. ZDM Mathematics Education, 48(5), 691-719.

Sinclair, N., Bartolini Bussi, M. G., de Villiers, M., Jones, K., Kortenkamp, U., Leung, A., \& Owens, K. (2016). Recent research on geometry education: An ICME-13 survey team report. ZDMMathematics Education, 48(5), 691-719.

van Hiele, P. M. (1984). A child's thought and geometry. In D. Fuys, D. Geddes and R. W. Tischler (Eds.) (1959/1985) English Translation of Selected Writings of Dina van Hiele-Geldof and Pierre M. van Hiele (pp.243-252). Washington, D.C. :NSF.

van Nes, F., \& van Eerde, D. (2010). Spatial structuring and the development of number sense: A 
case study of young children working with blocks. The Journal of Mathematical Behavior, 29(3), 145-159.

Ward Jr, J. H. (1963). Hierarchical grouping to optimize an objective function. Journal of the American Statistical Association, 58(301), 236-244.

Widder, M., \& Gorsky, P. (2013). How students use a software application for visualizing 3D geometric objects to solve problems. Journal of Computers in Mathematics and Science Teaching, $32(1), 89-120$.

Yackel, E., Cobb, P., \& Wood, T. (1991). Small-group interactions as a source of learning opportunities in second-grade mathematics. Journal for Research in Mathematics Education, 22(5), 390-408. 